\title{
Pathological aspects of bioresorbable stent implantation
}

\author{
Oscar D. Sanchez ${ }^{1}, \mathrm{MD}$; Kazuyuki Yahagi ${ }^{1}$, MD; Robert A. Byrne ${ }^{2}, \mathrm{MB}, \mathrm{BCh}, \mathrm{PhD}$; Hiroyoshi Mori ${ }^{1}$, MD; \\ Roya Zarpak ${ }^{1}$, MS; Eric Wittchow ${ }^{1}$, PhD; Nicolas Foin ${ }^{3}$, MSc, PhD; Renu Virmani ${ }^{1}$, MD; Michael Joner ${ }^{*}$, MD \\ 1. CVPath Institute, Inc., Gaithersburg, MD, USA; 2. Deutsches Herzzentrum München, Technische Universität München, \\ Munich, Germany; 3. National Heart Centre Singapore, Singapore
}

The references can be found in the online version of this paper at the following website: http://www.pcronline.com/eurointervention/V_issue/39

\section{KEYWORDS}

- bifurcation stenting

- bioresorbable stent

- coronary artery

disease

- drug-eluting stent

- histopathology

\section{Abstract}

The treatment of obstructive coronary artery disease has been revolutionised by the advent of drug-eluting stent therapy. However, concerns remain about complications late after stent implantation including late stent thrombosis, hypersensitivity reactions and neoatherosclerosis. In this respect, the introduction of fully bioresorbable stents (BRS) - which resorb over time and leave the arterial wall free of any metal constraints - represents a potentially important disruptive technology. However, although the concept is intuitively attractive, a thorough understanding of the histopathological changes seen after BRS implantation and an appreciation of comparative changes versus existing metal stent technologies are vital to guide BRS clinical usage. In this respect, translational investigation of polymer chemistry, biomedical engineering, as well as in vitro and in vivo testing in animal models is an important undertaking. This article will review the pathological aspects of BRS implantation with a focus on acute and chronic vascular reactions derived from preclinical animal studies, including insights from in vivo imaging. Finally, potential future directions of this novel therapeutic approach will be discussed.

*Corresponding author: CVPath Institute, Inc., 19 Firstfield Road, Gaithersburg, MD, 20878, USA.

E-mail:mjoner@cvpath.org 


\section{Introduction}

Complications due to coronary artery disease are the leading cause of death worldwide, and percutaneous coronary intervention (PCI) is the dominant treatment modality for patients with obstructive disease patterns. While PCI treatment with implantation of bare metal stents was hampered by high rates of restenosis, these limitations were largely addressed with the introduction of drug-eluting stents (DES), resulting in effective inhibition of neointimal hyperplasia - the predominant cause of restenosis after bare metal stenting. However, these improvements occurred at the cost of delayed healing of the stented arterial segment. Delayed arterial healing is characterised by the persistence of peri-strut fibrin deposition, inflammatory cell infiltration and incomplete endothelial coverage. Together these changes are well recognised as a pathological correlate of increased risk of late stent thrombosis ${ }^{1}$. Moreover, delayed healing following DES implantation at nine to 12 months was accompanied by slow but steady late catch-up in neointimal growth in a recent clinical study ${ }^{2}$. Second-generation DES clearly outperformed their first-generation counterparts with respect to improved vascular healing while maintaining efficacy, achieving sustained inhibition in neointimal growth ${ }^{3}$. Nevertheless, important limitations remain with current-generation DES, including in-stent neoatherosclerosis, sustained vasomotor dysfunction and late catch-up restenosis - issues which make further technological iteration an important undertaking.

Initially tested in clinical trials in the late 1990s, fully bioresorbable stents (BRS) are a breakthrough technology with the potential to revolutionise PCI treatment of obstructive atherosclerotic lesions. Although conceptually appealing, a thorough understanding of this technology requires fundamental knowledge of polymer chemistry, biomedical engineering and vascular biology. This review article focuses on the pathologic aspects of BRS implantation in animals and the implications for clinical practice, and aims to provide relevant insights specific to the implantation of BRS in bifurcation lesions.

\section{From the past to current bioresorbable stent technologies}

Development of BRS technology dates back to the early $1990 \mathrm{~s}^{4}$, with Tamai et al being the first to report clinical experience with the IgakiTamai fully bioabsorbable stent (Igaki Medical Planning Company, Kyoto, Japan), which was made of poly-L-lactic acid (PLLA) without drug coating 5 . Following on from this, many BRS technologies have been developed and reached clinical testing, and two successor devices received CE mark approval in Europe - the Absorb Bioresorbable Vascular Scaffold (BVS; Abbott Vascular, Santa Clara, CA, USA), which comprises a PLLA backbone and a poly-DL-lactic acid (PDLLA) coating containing everolimus at a concentration of $8.2 \mu \mathrm{g} / \mathrm{mm}$ with strut thickness of $156 \mu \mathrm{m}^{6}$, and the DESolve stent (Elixir Medical, Sunnyvale, CA, USA), also made of PLLA, eluting myolimus at a concentration of $3.0 \mu \mathrm{g} / \mathrm{mm}$ with $150 \mu \mathrm{m}$ strut thickness ${ }^{7}$. In contrast to the Igaki-Tamai stent, current devices obviate the need for heat-facilitated expansion and are available with similar vascular access dimensions to those utilised in contemporary DES.
Metallic BRS have also been investigated for more than a decade. Drug-eluting BRS derived from magnesium and its alloys are being examined as part of the Drug-Eluting Absorbable Metal Scaffold (DREAMS) programme (Biotronik, Bülach, Switzerland) and have reached clinical investigation in the DREAMS-1 (paclitaxel) and 2 (sirolimus) trials. The metal scaffold has a strut thickness of 125 and $150 \mu \mathrm{m}$, respectively, with a resorption time of approximately nine to 12 months.

Other BRS are at different developmental stages. These include the ReZolve ${ }^{\mathrm{TM}}$ (Reva Medical, San Diego, CA, USA) BRS made from poly-tyrosine-derived polycarbonate (PTD-PC), eluting sirolimus with a strut thickness of $115-230 \mu \mathrm{m}$ and a resorption time of two to three years. The ART (Arterial Remodeling Technology, Paris, France) stent (without a drug coating) is composed of a PDLLA polymer, with strut thickness of $170 \mu \mathrm{m}$ and resorption time of two years. Early preclinical and clinical results have been promising?

\section{Preclinical evaluation of BRS HISTOPATHOLOGY}

Preclinical studies play a critical role in the evaluation of medical devices in general and coronary artery stents in particular. Histopathological evaluation of BRS is highly relevant for the prediction of device performance in clinical practice owing to the fact that important vascular reactions consequent on device degradation can only be examined in preclinical studies. Standard measurements for the preclinical assessment of DES have been described previously ${ }^{9}$, and similar techniques have been used for the assessment of BRS. In the assessment of BRS, the extent of injury to the arterial wall, degree of inflammation, and characterisation of degradation kinetics (molecular weight loss, strength and mass loss) are critical elements. Inflammation should be judged based on the extent of acute and chronic inflammatory cell infiltration at various time points. Moreover, it is important to correlate inflammation with the extent of subsequent arterial remodelling. Importantly, standard injury scores may be misleading in long-term implant follow-up, as destruction of the internal elastic lamina may result from inflammation rather than reflecting vascular residues of acute injury at the time of stent implantation. Furthermore, a special effort should be made to characterise the change in tissue response during biodegradation focusing on both the extent and nature of neointimal tissue, i.e., cell type and matrix characteristics, especially in the region of the resorption sites in the vicinity of stent struts.

\section{INTRAVASCULAR IMAGING}

Intravascular imaging modalities, such as intravascular ultrasound (IVUS) and optical coherence tomography (OCT), are useful tools in the assessment of coronary stents ${ }^{10-14}$. High-resolution modalities in particular allow for the evaluation of important in vivo healing parameters such as stent strut coverage, neointima formation, presence of malapposition and extent of thrombus formation. However, it is important to realise that intravascular image acquisition may in itself cause tissue damage - especially endothelial loss and even intimal 
or medial injury - and this may complicate correct histopathologic assessment. Nevertheless, intravascular imaging is recommended in a subset of study samples for the assessment of BRS degradation and in vivo vessel dimension assessment such that evaluations are carried out over time under normal physiologic pressures ${ }^{15}$.

\section{TIMING OF FOLLOW-UP}

In general, follow-up should capture all relevant biological processes pertaining to stent safety. If biodegradation of BRS components takes two years, time points beyond the two-year time frame will be necessary to capture device safety fully. In particular, evaluation of late time points after bioresorption is complete is required to document late patency of the vessel, extent of narrowing from neointima formation, and absence of late inflammation.

\section{BIOCHEMICAL ANALYSIS OF DEGRADATION PRODUCTS}

In general, all degradation products need to be clearly documented with respect to the physiochemical structure along with in vivo biological responses. With respect to the evaluation of polymeric components, gel permeation chromatography is a suitable analytical method to assess molecular weight and polydispersity index (PDI), which provide important insights into the degradation process of the stent and help explain observed biological behaviour. It is also important to correlate results of bioengineering tests with those from in vitro and in vivo degradation analysis to facilitate understanding of BRS integrity. For the assessment of metallic BRS devices, other technologies may be applied to examine degradation products appropriately, including chemical analysis, micro-CT analysis, and scanning electron microscopy with elemental analysis.

\section{Clinically relevant preclinical findings TIME COURSE OF BRS DEGRADATION}

Since BRS are designed to degrade over time, it seems intuitive that radial strength and stent degradation strongly correlate, as the latter critically determines mechanical integrity at a given time point. Interestingly, degradation of stent struts in the Absorb BVS has been reported to occur in a staggered manner, commencing with hydrolysis of amorphous connector chains and proceeding to subsequent degradation of the more crystalline backbone. Mass loss occurs only when oligomers are sufficiently small to escape the highly crystalline polymer matrix so that they can be taken up by macrophages. Decline in radial strength typically proceeds during the various phases of polymer degradation. While the main features of polymer degradation can be established in vitro, preclinical studies play an important role in the assessment of polymer biodegradation as crucial aspects of biological interactions can only be determined in vivo.

Otsuka et al recently reported the degradation profile of the Absorb (Version 1.1) BVS in a preclinical study with follow-up of four years ${ }^{16}$. Polymer absolute number molecular weight decreased slowly within the first six months but thereafter degraded rapidly with $93 \%$ loss at 24 months. Percent mass loss relative to maximum index mass was not significant until 18 months following implantation, with rapid mass loss occurring thereafter (Figure 1). In line

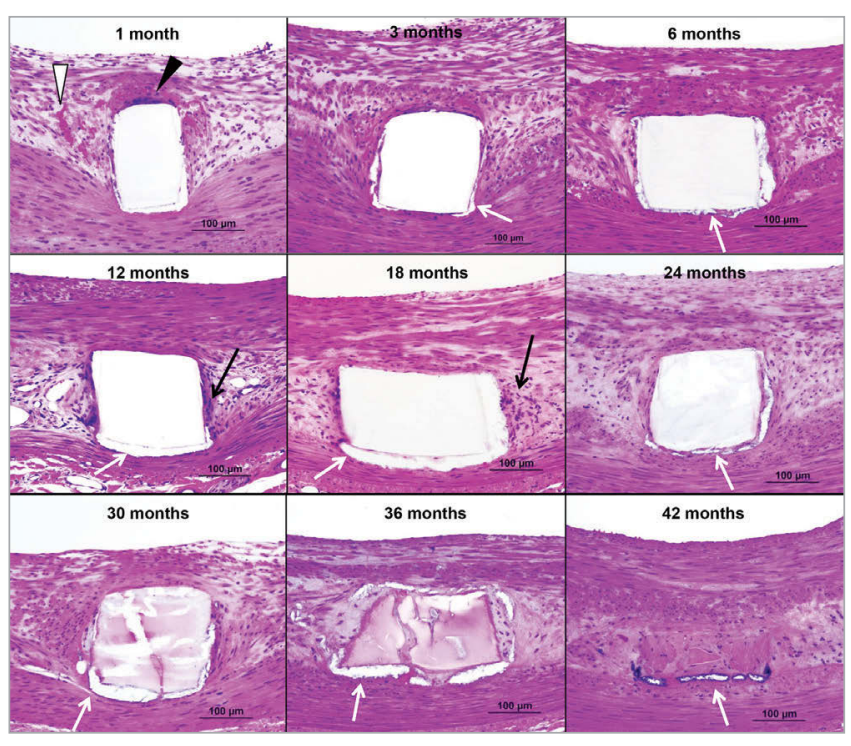

Figure 1. Inflammatory reaction after Absorb BVS implantation. Histologic images showing Absorb struts/resorption sites up to 42 months. Giant cells were observed at one month (black arrowheads) and were rare beyond three months. Highest fibrin deposition was found at one month (white arrowheads) with decrease at three months and absent thereafter. Mild inflammatory infiltrate (black arrows) was observed from 12 to 36 months and consisted typically of macrophages and lymphocytes. Minor areas of calcification (white arrows) were detected around struts/resorption sites after three months (haematoxylin and eosin stains). (Reproduced with permission from Otsuka et al, Circ Cardiovasc Interv. 2014;7:330-42)

with these findings, histological signs of dismantling struts were apparent only after 12 months, with complete resorption of stent struts observed between 36 and 42 months. The clinical implications of this study are important because, firstly, hydrolysis-based degradation of polymers is expected to be similar among animal models and man. The study by Otsuka et al represents a milestone not only as a reference for future preclinical investigations of novel BRS but also for clinical surveillance protocols of patients receiving currently approved BRS. On the other hand, the impact of disease conditions, such as underlying atherosclerosis with and without extensive calcification and diabetes, remains to be determined. Secondly, the pace of biodegradation largely influences radial strength and will therefore impact on the efficacy and safety profile of BRS. However, in the absence of histologic examination during clinical assessment, there remains a clear gap between the knowledge acquired in preclinical studies and its transferability to clinical practice. Future human autopsy data will probably permit important insights. However, at present, intravascular imaging utilising high-resolution frequency-domain OCT examination can provide important additional information on the degradation of BRS as a function of time. More importantly, correlation studies of histologic changes with OCT imaging have a great potential for the translation of pathological findings into clinical practice. 
Onuma et al correlated the histopathologic findings after implantation of the Absorb (Version 1.0) BVS with OCT imaging ${ }^{15}$. They described four fundamentally different levels of degradation based on the morphological appearance of stent struts by OCT: 1) immediately after implantation of the BRS in healthy porcine coronary arteries, polymeric stent struts exhibit a preserved box appearance, which is confirmed by histology; 2) at 28 days following implantation, the majority $(\sim 80 \%)$ of stent struts show a preserved box appearance and $\sim 20 \%$ of struts have an open box appearance; 3 ) at two years following implantation, approximately $80 \%$ of stent struts showed a preserved box appearance, another $17 \%$ of struts exhibited a dissolved black box appearance and only a few stent struts had an open box appearance; 4) finally, at four years, approximately $50 \%$ of stent struts appeared as a dissolved bright box while the remaining half of stent struts appeared as a dissolved black box (Figure 2). The corresponding histological findings at this time point revealed a predominance of stent strut sites being replaced by dense connective tissue with a paucity of smooth muscle cells and occasional basophilic appearance of stent strut sites.

From the above description it can be seen that there is significant heterogeneity in BRS strut degradation: while some stent struts show early signs of strut degradation by OCT (dissolved box appearance), others are well advanced, which will ultimately determine the time frame at which biodegradation will be considered complete. This heterogeneity may be especially important when bifurcation lesions are treated using BRS technology as the pace of biodegradation may be variable among stent struts embedded within the neointimal tissue in comparison with those located at the ostia of side branches and exposed to circulating blood for a prolonged period of time. Follow-up evaluation of the malapposed BRS stents in a left circumflex/left obtuse marginal bifurcation has been investigated using intravascular imaging in a case report of a 58-year-old man and revealed that degradation of BRS struts protruding into the main branch seemed to show delayed degradation in comparison to fully apposed and embedded struts in the side branch ${ }^{18}$. While these intriguing observations may be relevant for clinical practice, larger and specifically designed studies are needed to clarify the fate of degrading stent struts in bifurcation lesions.

\section{ENDOTHELIALISATION OF BRS}

Poor strut coverage and delayed arterial healing have been shown to be the main substrates responsible for late and very late stent thrombosis after early-generation DES stent placement ${ }^{1}$. However, second-generation DES exhibited a lower prevalence of uncovered struts, less inflammation, and less fibrin deposition versus early-generation DES in pathological studies ${ }^{3}$, confirming technological improvement with better understanding of vessel response. A recent preclinical study in healthy swine from our institute compared the Absorb (Version 1.1) BVS (the current clinical device) and the metallic XIENCE DES (Abbott Vascular) over an observation period of four years ${ }^{16}$. By scanning electron microscopy, both the Absorb BVS and the XIENCE DES showed complete stent strut coverage with mild neointimal growth and presence of endothelial cells at 28 days. Endothelial coverage observed at one month was

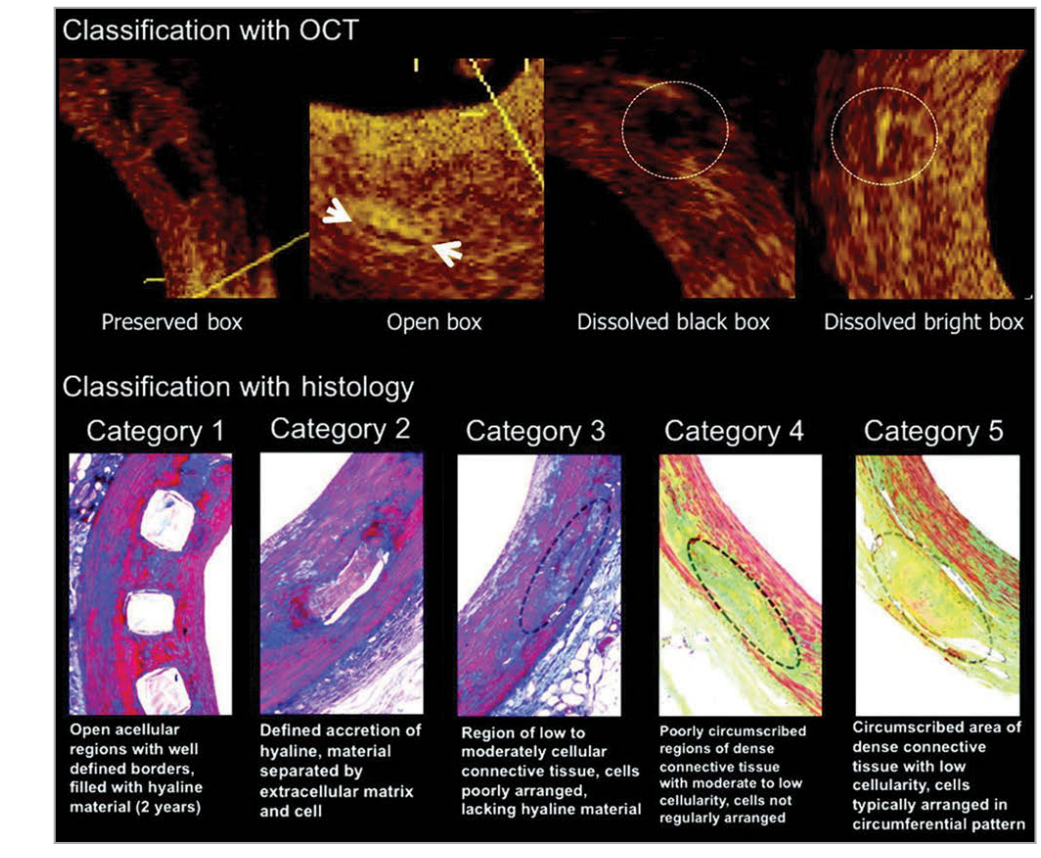

Figure 2. Classification of strut degradation evaluated by OCT and histology in porcine coronary arteries. Upper boxes show optical coherence tomography (OCT) images of strut degradation over different time points. Four categories are described: Preserved box, a box appearance image with sharply defined borders; Open box, with long-axis borders thickness and short-axis borders not visible; Dissolved black box, black spot with poorly defined borders; Dissolved bright box, partially visible bright spot. The lower images show histological degradation from category 1, open acellular struts, to category 5, dense connective tissue. (Reproduced with permission from Onuma et al ${ }^{15}$ ) 
maintained at 12-month follow-up ${ }^{16}$. Neither stent showed evidence of luminal thrombosis up to four years. However, it needs to be recognised that these data were acquired in healthy swine, which have been shown to exhibit a more rapid healing response compared to other species and $\operatorname{man}^{18}$. In a preceding version of the Absorb BVS (Version 1.0) it was reported that there was substantially less endothelial coverage at 28 days in the rabbit iliac artery model ${ }^{19}$ as compared to the rate reported in swine ${ }^{20}$ (Figure 3 ), which may be explained by the difference in design and the animal model used.

\section{CLINICAL IMPLICATIONS OF ACUTE THROMBOGENICITY IN BIFURCATION LESIONS}

Nakazawa et al investigated the impact of DES implantation on vascular healing in bifurcation lesions in comparison to age-matched bare metal stent counterparts. They described greater plaque thickness and necrotic core on the lateral compared to the flow divider (carina) wall ${ }^{21}$. Arterial healing of stent struts was impaired to a greater extent at the carina compared to the lateral wall, with greater fibrin deposition and uncovered stent struts being observed at the carina. These striking autopsy data were supported by findings from in vitro flow model studies showing the occurrence of turbulent flow and low shear stress at the carina after stent implantation in bifurcations ${ }^{21}$ (Figure 4). Recently, small-to-medium-sized clinical trials have demonstrated safety and efficacy following implantation of the Absorb (Version 1.1) BVS in non-complex lesions in patients with stable coronary disease ${ }^{22,23}$. However, an increasing number of case reports of BRS thrombosis

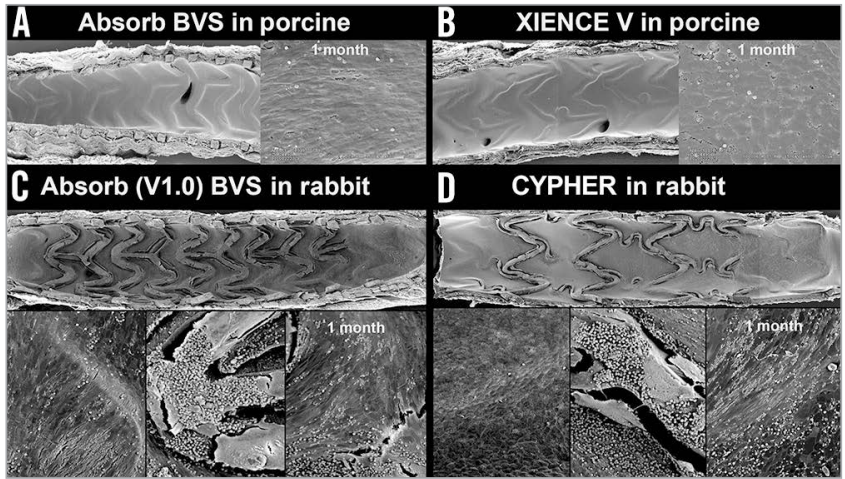

Figure 3. Differences in endothelial healing after BRS implantation among animal models. While complete endothelial coverage of BRS stent struts is observed in the healthy porcine model at 28 days in Absorb BVS (A) and XIENCE V (B), incomplete endothelial healing is seen in rabbit iliac arteries in Absorb (Version 1.0) (C) and CYPHER $^{\circledR}$ (Cordis, Johnson \& Johnson, Bridgewater, NJ, USA) (D). (Reproduced with permission from Otsuka et $\mathrm{al}^{16}$ )

have also been published of a variety of clinical scenarios ${ }^{24,25}$, and concern exists regarding a small but potentially important increased risk of stent thrombosis in comparison with contemporary $\mathrm{DES}^{26}$. Moreover, it has been proposed that increased acute thrombogenicity is related to the activation of coagulation pathways secondary to flow disturbances from bulky stent struts protruding into the lumen, which probably play a pivotal role in the pathophysiology of scaffold thrombosis early after

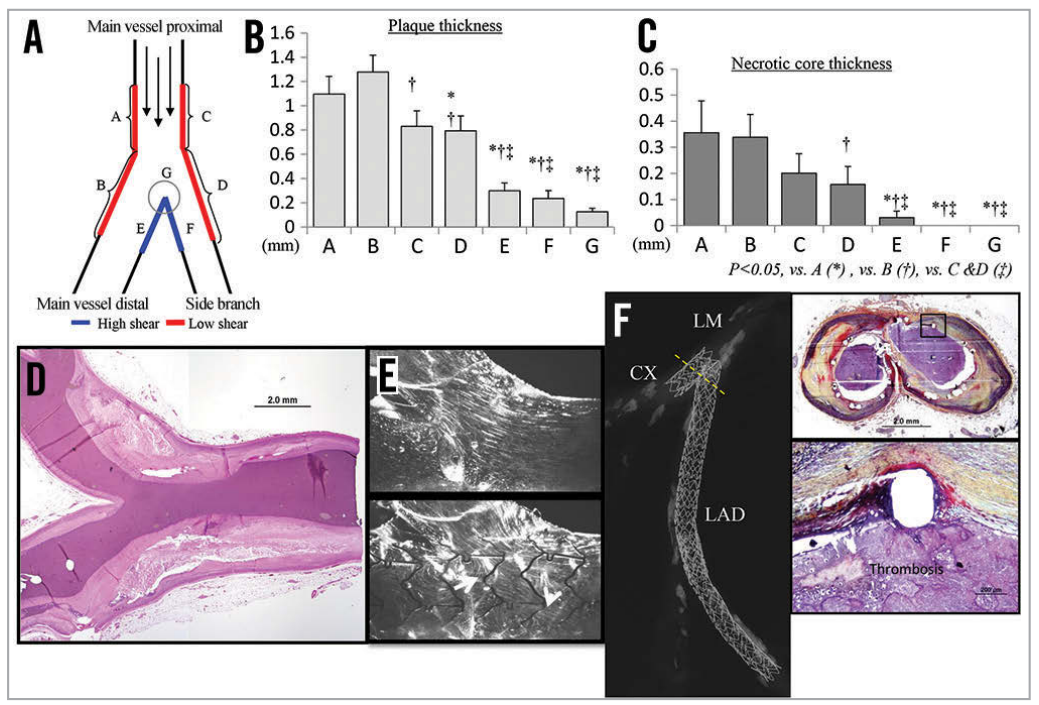

Figure 4. Pathology of bifurcation lesions. A) For the comparison between flow divider and lateral wall, morphometric and pathologic analysis was performed at the bifurcation site. B) Bar chart showing the plaque thickness in each region. C) Bar chart showing the presence of necrotic core. D) Low shear areas had a higher prevalence of coronary plaque as well as necrotic core. Note, carina involvement was rarely observed. E) The flow prior to stenting in our bifurcation model displayed laminar flow with no vortical structures within the downstream and upstream of the carina. The presence of the stent increased the overall flow disturbance within the bifurcation model, and the incidence of vortical structures and lateral flow separation increased at the carina region after stenting. F) A 55-year-old male with risk factors received three TAXUS ${ }^{\mathrm{TM}}$ stents (Boston Scientific, Marlborough, MA, USA) in the ostium of the left anterior descending coronary artery (LAD) and left circumflex (CX), and died suddenly two years after stent implantation. Radiograph shows mild calcified coronary artery with bifurcation stenting. Both stents are occluded with platelet-rich thrombus (Thr) at the ostium of LAD and CX. High magnification images show adherent thrombi on the uncovered struts. (Reproduced with permission from Nakazawa et al ${ }^{21}$ ) 
implantation (Figure 5). Beyond that, there are additional factors influencing acute thrombogenicity of stents such as underexpansion, fracture, distal vessel run-off and also patient-specific factors ${ }^{27,28}$.

Dual antiplatelet therapy plays a particularly important role in the setting of PCI for bifurcation lesions where biomechanical and haemodynamic factors may predispose to increased thrombogenicity and a requirement for more protracted or more potent antiplatelet therapy ${ }^{21}$. In an elegant study by Ormiston et al, side branch dilatation and mini-kissing balloon post-dilatation with non-compliant balloons following implantation of the Absorb BVS was investigated in a phantom model ${ }^{29}$. It was reported that side branch dilatation was accompanied by strut fracture when balloon inflation pressure exceeded 14 atmospheres. This was also seen when the main branch was post-dilated or mini-kissing balloon post-dilatation was performed. This study has clinical relevance in that it introduces a non-linear relationship between strut fracture of BRS and the aggressiveness of side branch and main branch post-dilatation. Despite the understanding of the likely detrimental consequences when implanting BRS in bifurcation lesions, there is an absence of preclinical and clinical data. Therefore, dedicated studies are needed to investigate the impact of stent distortion caused during endovascular procedures on clinical endpoints.

\section{BIORESORBABLE SCAFFOLDS AND VASCULAR REMODELLING}

Metallic stents alter the vascular geometry and biomechanics by inducing permanent and rigid constraints on the underlying arterial wall, which lead to flow disturbances and chronic inflammation ${ }^{30}$. Furthermore, these sustained restrictive forces prohibit adaptive vessel remodelling observed during atherosclerotic plaque progression. Considering the highly preserved nature of this phenomenon in vascular biology, the impact on long-term vessel physiology is probably considerable ${ }^{31}$. BRS offer a return of vascular pliability in the long term. Consequently, the vessel rigidity following stent implantation is only transient, which may be of particular relevance in bifurcation lesions ${ }^{32}$. Also, vessel pulsatility, vasomotion and distensibility have been shown to recover at least partially following bioresorbable scaffold degradation at nine to 12 months $^{33}$. However, most of the above potential advantages with BRS remain hypothetical, and large-scale clinical trials with long-term followup will be necessary to investigate potential clinical relevance.

One of the most striking features of BRS technology is the substantial increase in lumen area observed in preclinical animal studies and confirmed in long-term imaging surveillance of a small number of patients receiving Absorb BVS ${ }^{17,34}$. A large preclinical study in juvenile normal porcine arteries reported expansive vascular remodelling starting after 12 months ${ }^{17}$. However, it is possible that in part the lumen gain may reflect animal growth. In this study, a total of 263 Absorb (Version 1.1) BVS implanted in the swine model were angiographically and histologically investigated for vascular reactions and strut degradation as a function of time. Both angiography and histopathology confirmed the expansive remodelling following BRS implantation beyond 12 months, which was not observed in control metallic DES. Despite the greater percent stenosis and neointimal thickening observed with the BRS compared to the DES, expansive remodelling resulted in a net gain of lumen area over time. Moreover, this knowledge was gained in normal arteries, and the influence of underlying atherosclerosis on vessel remodelling following BRS implantation has only been assessed in a small number of patients. Although encouraging results have been reported in small clinical studies, larger trials in complex coronary pathology are needed to determine the full impact of current BRS on expansive remodelling.

The presence of macrophages, with overexpression of matrix metalloproteinases (MMPs) such as MMP 2, 3 and 13 probably play a pivotal role during vascular remodelling in atherosclerotic vessels ${ }^{35}$. The luminal gain during early progression of atherosclerotic lesions is a dynamic process involving the interplay of inflammatory cells

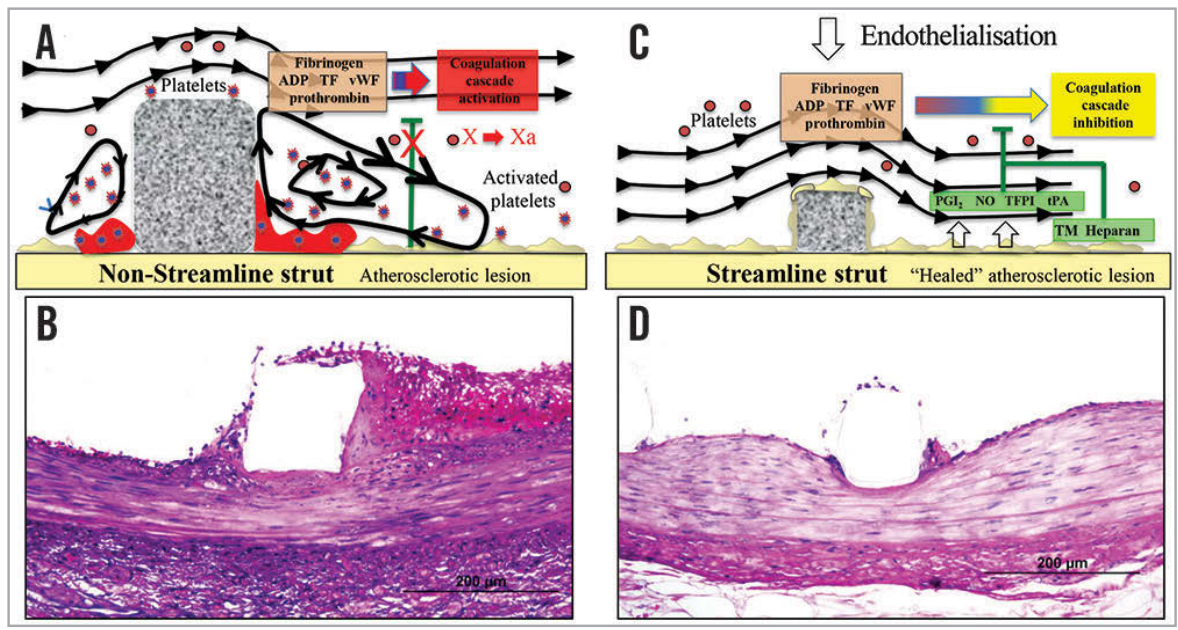

Figure 5. Strut thickness impact on flow pattern and endothelialisation. A) Non-streamlined struts generate turbulent flow in areas of low shear stress, provoke activation of the coagulation cascade and the generation of thrombus. B) Histological counterpart of a non-streamlined stent strut (approx. $150 \mu \mathrm{m}$ ) showing acute thrombus formation in the area of low shear stress in a juvenile porcine model three days after implantation. C) Streamlined stent struts do not generate turbulent flow in regions of low shear stress, and, consequently, there is less thrombus formation in these areas (D). (A and C are modified with permission from Jimenez JM et al, Annals of Biomedical Engineering. 2009; 37:1483-94) 
and vascular smooth muscle cells. However, late changes in vessel wall composition secondary to molecular interactions between cells and matrix components are more complex and have been described in pioneering pathological studies involving animal models and human studies ${ }^{36,37}$. Some of these seminal observations from previous studies may be transferable to the vascular changes observed following BRS implantation (Figure 6). Necrotic core enlargement and the presence of calcification have been reported to correlate with positive remodelling ${ }^{37}$. Smooth muscle cell apoptosis resulting in medial wall thinning has also been shown to occur in animal models and correlates with vessel remodelling ${ }^{38}$. These groundbreaking pathological observations reinforce the notion that arterial microenvironment and plaque-associated inflammatory responses may have a profound impact on vascular remodelling, even after implantation of BRS.

Recent understanding of vascular remodelling highlights the complex interplay of shear-stress-induced molecular pathways that generate changes in vessel composition in native and diseased arteries ${ }^{39}$. According to Korshunov et al, vascular remodelling is also facilitated
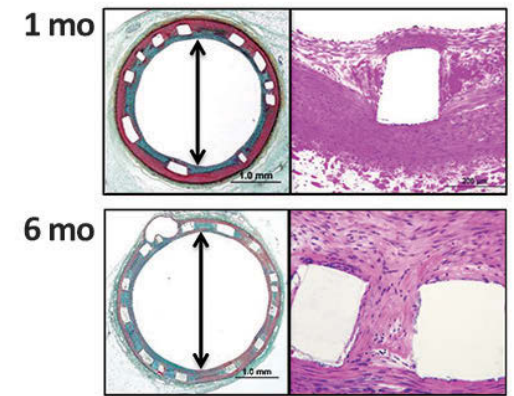

$18 \mathrm{mo}$
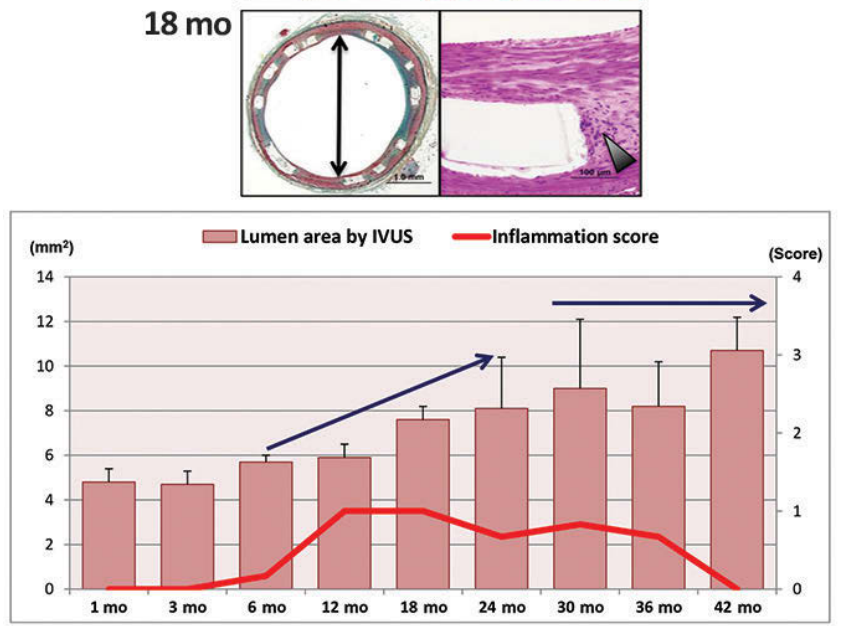

Figure 6. Association between inflammatory reaction and lumen area by IVUS following Absorb implantation in porcine coronary arteries. A) Representative histological images of Absorb at one, six, and 18 months. Arrowhead=inflammatory cells. B) The red line represents inflammation score and the pink bars show lumen area by IVUS, which are presented as mean \pm standard deviation (SD). Inflammatory reaction in Absorb increased from six months and peaked at 12 months, which decreases over time. Lumen area increased gradually from 12 months up to 24 months, which was maintained up to 42 months. (Reproduced with permission from Otsuka et al ${ }^{16}$ ) by alterations in shear stress: high shear stress regions show reduction in plaque size and larger lumen without changes in vessel size. In contrast, regions of low shear stress are the predominant areas of positive remodelling with maintenance of lumen area secondary to compensatory enlargement of vessel size. While these studies certainly require further validation, there is no doubt that understanding of molecular pathways along with histopathologic changes during vascular remodelling after BRS implantation are needed in order to provide meaningful insights into clinically relevant processes induced by this technology. These highly dynamic and biologically complex processes may be further modified in the setting of arterial bifurcations due to flow dynamics and atherosclerotic processes when it comes to stent implantation. Furthermore, the presence of strut fractures, which are more likely to occur at bifurcation sites, may also prevent or further facilitate expansive remodelling observed with BRS technology. These observations underscore the relevance and need for dedicated preclinical and clinical studies.

\section{Conclusion}

Fully resorbable BRS undoubtedly represent an important iterative development of stent technology, which holds great promise for eliminating some of the limitations of current-generation DES technology, particularly in relation to late adverse events. However, these potential advantages require investigation in large-scale clinical trials with long-term follow-up. Pathologic assessment and high-resolution intravascular imaging of BRS provide valuable insights into the vascular reactions induced by these devices, and detailed elucidation of these processes will probably play an important role in the future iterative refinement of this technology. The key distinguishing feature of BRS technology is the process of vascular remodelling during polymer degradation, which provides an opportunity for the management of progression of atherosclerosis but may also lead to potentially maladaptive vessel wall changes. Moreover, considering the relevance of PCI for bifurcation lesions in daily clinical practice, future device iterations of BRS will probably be needed to permit reliable treatment of this important lesion subset and facilitate expansion of this young technology to increasingly complex disease morphology.

\section{Conflict of interest statement}

M. Joner is a consultant for Biotronik and Cardionovum, and has received speaking honoraria from Abbott Vascular, Biotronik, Medtronic, and St. Jude. R. Virmani receives research support from Abbott Vascular, Biosensors International, Biotronik, Boston Scientific, Medtronic, MicroPort Medical, OrbusNeich Medical, SINO Medical Technology, and Terumo Corporation; has speaking engagements with Merck; receives honoraria from Abbott Vascular, Boston Scientific, Lutonix, Medtronic, and Terumo Corporation; and is a consultant for 480 Biomedical, Abbott Vascular, Medtronic, and W.L. Gore. The other authors have no conflicts of interest to declare.

\section{References}

The references can be found in the online version of the paper. 


\section{Online data supplement}

\section{References}

1. Joner M, Finn AV, Farb A, Mont EK, Kolodgie FD, Ladich E, Kutys R, Skorija K, Gold HK, Virmani R. Pathology of drug-eluting stents in humans: delayed healing and late thrombotic risk. $J \mathrm{Am}$ Coll Cardiol. 2006;48:193-202.

2. Iijima R, Araki T, Nagashima Y, Yamazaki K, Utsunomiya M, Hori M, Itaya H, Shinji H, Shiba M, Hara H, Nakamura M, Sugi K. Incidence and predictors of the late catch-up phenomenon after drug-eluting stent implantation. Int $J$ Cardiol. 2013;168: 2588-92.

3. Otsuka F, Vorpahl M, Nakano M, Foerst J, Newell JB, Sakakura K, Kutys R, Ladich E, Finn AV, Kolodgie FD, Virmani R. Pathology of second-generation everolimus-eluting stents versus first-generation sirolimus- and Paclitaxel-eluting stents in humans. Circulation. 2014;129:211-23.

4. van der Giessen WJ, Slager CJ, van Beusekom HM, van Ingen Schenau DS, Huijts RA, Schuurbiers JC, de Klein WJ, Serruys PW, Verdouw PD. Development of a polymer endovascular prosthesis and its implantation in porcine arteries. J Interv Cardiol. 1992;5:175-85.

5. Tamai H, Igaki K, Kyo E, Kosuga K, Kawashima A, Matsui S, Komori H, Tsuji T, Motohara S, Uehata H. Initial and 6-month results of biodegradable poly-1-lactic acid coronary stents in humans. Circulation. 2000;102:399-404.

6. Gogas BD, Farooq V, Onuma Y, Serruys PW. The ABSORB bioresorbable vascular scaffold: an evolution or revolution in interventional cardiology? Hellenic J Cardiol. 2012;53:301-9.

7. Verheye S, Ormiston JA, Stewart J, Webster M, Sanidas E, Costa R, Costa JR Jr, Chamie D, Abizaid AS, Pinto I, Morrison L, Toyloy S, Bhat V, Yan J, Abizaid A. A next-generation bioresorbable coronary scaffold system: from bench to first clinical evaluation: 6- and 12-month clinical and multimodality imaging results. JACC Cardiovasc Interv. 2014;7:89-99.

8. Joner M, Byrne RA. The importance of preclinical research in contemporary interventional cardiology. EuroIntervention. 2010;6: 19-23.

9. Schwartz RS, Edelman ER, Carter A, Chronos N, Rogers C, Robinson KA, Waksman R, Weinberger J, Wilensky RL, Jensen DN, Zuckerman BD, Virmani R; Consensus Committee. Drug-eluting stents in preclinical studies: recommended evaluation from a consensus group. Circulation. 2002;106:1867-73.

10. Nissen SE, Gurley JC, Grines CL, Booth DC, McClure R, Berk M, Fischer C, DeMaria AN. Intravascular ultrasound assessment of lumen size and wall morphology in normal subjects and patients with coronary artery disease. Circulation. 1991;84: 1087-99.

11. Mintz GS, Kent KM, Pichard AD, Satler LF, Popma JJ, Leon MB. Contribution of inadequate arterial remodeling to the development of focal coronary artery stenoses. An intravascular ultrasound study. Circulation. 1997;95:1791-8.
12. Huang D, Swanson EA, Lin CP, Schuman JS, Stinson WG, Chang W, Hee MR, Flotte T, Gregory K, Puliafito CA, et al. Optical coherence tomography. Science. 1991;254:1178-81.

13. Kawase Y, Hoshino K, Yoneyama R, McGregor J, Hajjar RJ, Jang IK, Hayase M. In vivo volumetric analysis of coronary stent using optical coherence tomography with a novel balloon occlusion-flushing catheter: a comparison with intravascular ultrasound. Ultrasound Med Biol. 2005;31:1343-9.

14. Yun SH, Tearney GJ, Vakoc BJ, Shishkov M, Oh WY, Desjardins AE, Suter MJ, Chan RC, Evans JA, Jang IK, Nishioka NS, de Boer JF, Bouma BE. Comprehensive volumetric optical microscopy in vivo. Nat Med. 2006;12:1429-33.

15. Onuma Y, Serruys PW, Perkins LE, Okamura T, Gonzalo N, Garcia-Garcia HM, Regar E, Kamberi M, Powers JC, Rapoza R, van Beusekom H, van der Giessen W, Virmani R. Intracoronary optical coherence tomography and histology at 1 month and 2, 3, and 4 years after implantation of everolimus-eluting bioresorbable vascular scaffolds in a porcine coronary artery model: an attempt to decipher the human optical coherence tomography images in the ABSORB trial. Circulation. 2010;122:2288-300.

16. Otsuka F, Pacheco E, Perkins LE, Lane JP, Wang Q, Kamberi M, Frie M, Wang J, Sakakura K, Yahagi K, Ladich E, Rapoza RJ, Kolodgie FD, Virmani R. Long-term safety of an everolimus-eluting bioresorbable vascular scaffold and the cobaltchromium XIENCE V stent in a porcine coronary artery model. Circ Cardiovasc Interv. 2014;7:330-42.

17. Danson E, Bhindi R, Hansen P. Follow-up evaluation of unapposed bioresorbable vascular scaffold at a coronary bifurcation using optical coherence tomography. Int J Cardiol. 2014;177:e84-6.

18. Llano R, Winsor-Hines D, Patel DB, Seifert PS, Hamamdzic D, Wilson GJ, Wang H, Keane MG, Huibregtse BA, Wilensky RL. Vascular responses to drug-eluting and bare metal stents in diabetic/ hypercholesterolemic and nonatherosclerotic porcine coronary arteries. Circ Cardiovasc Interv. 2011;4:438-46.

19. Vorpahl M, Nakano M, Perkins LE, Otsuka F, Jones R, Acampado E, Lane JP, Rapoza R, Kolodgie FD, Virmani R. Vascular healing and integration of a fully bioresorbable everolimus-eluting scaffold in a rabbitiliac arterial model. EuroIntervention. 2014;10:833-41.

20. Gogas BD, Radu M, Onuma Y, Perkins L, Powers JC, GomezLara J, Farooq V, Garcia-Garcia HM, Diletti R, Rapoza R, Virmani R, Serruys PW. Evaluation with in vivo optical coherence tomography and histology of the vascular effects of the everolimuseluting bioresorbable vascular scaffold at two years following implantation in a healthy porcine coronary artery model: implications of pilot results for future pre-clinical studies. Int J Cardiovasc Imaging. 2012;28:499-511.

21. Nakazawa G, Yazdani SK, Finn AV, Vorpahl M, Kolodgie FD, Virmani R. Pathological findings at bifurcation lesions: the impact 
of flow distribution on atherosclerosis and arterial healing after stent implantation. J Am Coll Cardiol. 2010;55:1679-87.

22. Serruys PW, Ormiston JA, Onuma Y, Regar E, Gonzalo N, Garcia-Garcia HM, Nieman K, Bruining N, Dorange C, MiquelHébert K, Veldhof S, Webster M, Thuesen L, Dudek D. A bioabsorbable everolimus-eluting coronary stent system (ABSORB): 2-year outcomes and results from multiple imaging methods. Lancet. 2009;373:897-910.

23. Serruys PW, Chevalier B, Dudek D, Cequier A, Carrie D, Iniguez A, Dominici M, van der Schaaf RJ, Haude M, Wasungu L, Veldhof S, Peng L, Staehr P, Grundeken MJ, Ishibashi Y, GarciaGarcia HM, Onuma Y. A bioresorbable everolimus-eluting scaffold versus a metallic everolimus-eluting stent for ischaemic heart disease caused by de-novo native coronary artery lesions (ABSORB II): an interim 1-year analysis of clinical and procedural secondary outcomes from a randomised controlled trial. Lancet. 2015;385: 43-54.

24. Miyazaki T, Panoulas VF, Sato K, Naganuma T, Latib A, Colombo A. Acute stent thrombosis of a bioresorbable vascular scaffold implanted for ST-segment elevation myocardial infarction. Int J Cardiol. 2014;174:e72-4.

25. Karanasos A, van Geuns RJ, Zijlstra F, Regar E. Very late bioresorbable scaffold thrombosis after discontinuation of dual antiplatelet therapy. Eur Heart J. 2014;35:1781.

26. Byrne RA, Kastrati A. Bioresorbable drug-eluting stents: an immature technology in need of mature application. JACC Cardiovasc Interv. 2015;8:198-200.

27. Rogers C, Edelman ER. Endovascular stent design dictates experimental restenosis and thrombosis. Circulation. 1995;91: 2995-3001.

28. Kolandaivelu K, Swaminathan R, Gibson WJ, Kolachalama VB, Nguyen-Ehrenreich KL, Giddings VL, Coleman L, Wong GK, Edelman ER. Stent thrombogenicity early in high-risk interventional settings is driven by stent design and deployment and protected by polymer-drug coatings. Circulation. 2011;123:1400-9.

29. Ormiston JA, Webber B, Ubod B, Webster MW, White J. Absorb everolimus-eluting bioresorbable scaffolds in coronary bifurcations: a bench study of deployment, side branch dilatation and post-dilatation strategies. EuroIntervention. 2015;10:1169-77.

30. Wentzel JJ, Whelan DM, van der Giessen WJ, van Beusekom HM, Andhyiswara I, Serruys PW, Slager CJ, Krams R.
Coronary stent implantation changes 3-D vessel geometry and 3-D shear stress distribution. J Biomech. 2000;33:1287-95.

31. Glagov S, Weisenberg E, Zarins CK, Stankunavicius R, Kolettis GJ. Compensatory enlargement of human atherosclerotic coronary arteries. $N$ Engl J Med. 1987;316:1371-5.

32. Gomez-Lara J, Garcia-Garcia HM, Onuma Y, Garg S, Regar E, De Bruyne B, Windecker S, McClean D, Thuesen L, Dudek D, Koolen J, Whitbourn R, Smits PC, Chevalier B, Dorange C, Veldhof S, Morel MA, de Vries T, Ormiston JA, Serruys PW. A comparison of the conformability of everolimuseluting bioresorbable vascular scaffolds to metal platform coronary stents. JACC Cardiovasc Interv. 2010;3:1190-8.

33. Brugaletta S, Heo JH, Garcia-Garcia HM, Farooq V, van Geuns RJ, de Bruyne B, Dudek D, Smits PC, Koolen J, McClean D, Dorange C, Veldhof S, Rapoza R, Onuma Y, Bruining N, Ormiston JA, Serruys PW. Endothelial-dependent vasomotion in a coronary segment treated by ABSORB everolimus-eluting bioresorbable vascular scaffold system is related to plaque composition at the time of bioresorption of the polymer: indirect finding of vascular reparative therapy? Eur Heart J. 2012;33: 1325-33.

34. Simsek C, Karanasos A, Magro M, Garcia-Garcia HM, Onuma Y, Regar E, Boersma E, Serruys PW, van Geuns RJ. Longterm invasive follow-up of the everolimus-eluting bioresorbable vascular scaffold: five-year results of multiple invasive imaging modalities. EuroIntervention. 2014 Oct 28. [Epub ahead of print].

35. Newby AC. Matrix metalloproteinase inhibition therapy for vascular diseases. Vascul Pharmacol. 2012;56:232-44.

36. Newby AC. Metalloproteinase expression in monocytes and macrophages and its relationship to atherosclerotic plaque instability. Arterioscler Thromb Vasc Biol. 2008;28:2108-14.

37. Burke AP, Kolodgie FD, Farb A, Weber D, Virmani R. Morphological predictors of arterial remodeling in coronary atherosclerosis. Circulation. 2002;105:297-303.

38. Bennett M, Yu H, Clarke M. Signalling from dead cells drives inflammation and vessel remodelling. Vascul Pharmacol. 2012;56:187-92.

39. Korshunov VA, Schwartz SM, Berk BC. Vascular remodeling: hemodynamic and biochemical mechanisms underlying Glagov's phenomenon. Arterioscler Thromb Vasc Biol. 2007;27:1722-8. 